\title{
Effect of Night Temperature on Pollen Characteristics, Growth, and Fruit Set in Tomato
}

\author{
Mary M. Peet \\ Department of Horticultural Science, Box 7609, North Carolina State University, Raleigh, \\ NC 27695-7609 \\ Michael Bartholemew ${ }^{1}$ \\ Department of Agricultural and Extension Education, North Carolina State University, Raleigh, \\ NC 27695-7681
}

Additional index words. heat stress, reproductive development, male-sterile, pollen fertility, chronic subacute high temperatures

\begin{abstract}
Lycopersicon esculentum Mill. 'Laura' plants were grown in the North Carolina State Univ. phytotron at 26C day temperature and $18,22,24$, or $26 \mathrm{C}$ night temperatures to determine the effects of night temperature on pollen characteristics, growth, fruit set, and early fruit growth. Total and percentage normal pollen grains were higher in plants grown at night temperatures of 18 and $22 \mathrm{C}$ than at 24 and $26 \mathrm{C}$, but germination was highest in pollen produced at $26 \mathrm{C}$. Seed content was rated higher on the plants grown at $18 \mathrm{C}$ night temperatures than in any of the other treatments. Numbers of flowers and fruit on the first cluster were lower in the $26 \mathrm{C}$ night treatment than in the other night temperature treatments. Plant height was greatest but total shoot dry mass was lowest in the $22 \mathrm{C}$ night temperature treatments. Fruit fresh mass increased with night temperature, reflecting more rapid development, but the experiment was not continued to fruit maturity, so the effect of night temperature on final fruit size and total plant production could not be determined. Night temperatures of $26 \mathrm{C}$ reduced fruit number and percentage fruit set only slightly at a day temperature of $26 \mathrm{C}$, even though these temperatures were above optimal for pollen production and seed formation. To separate temperature effects on pollen from direct or developmental effects on female reproductive structures, pollen was collected from plants in the four night temperature treatments and applied to stigmas of a male-sterile cultivar kept at 24-18C minimum temperatures in adjacent greenhouses. In the greenhouse-grown male sterile plants, no consistent effects of night temperature treatment given the pollen could be seen in fruit set, fruit mass, seed content (either on a rating or seed count basis), seedling germination, or seedling dry mass.
\end{abstract}

High temperatures have been reported to limit tomato production wherever days are warmer than 32C, or nights are warmer than 21C (Moore and Thomas, 1952). Because of this high temperature sensitivity, poor fruit set is an important limitation to tomato production in the tropics (Villareal, 1980). Poor fruit set can also be a problem in the southern United States. In Louisiana, summer fruit set of six tomato genotypes ranged from $50 \%$ to $1 \%$ (Hanna and Hernandez, 1982). The importance of high temperatures in general, and high night temperatures in particular, as a production limitation for tomatoes and other crops may increase if current climatic trends continue. The National Oceanic and Atmospheric Administration reports that an examination of day and night temperatures at hundreds of climate stations in the United States, China, and areas included in the former Soviet Union, showed that average high temperature at night increased $0.7 \mathrm{C}$ during the last 40 years (Karl et al., 1991), but daytime temperatures were generally constant. They attributed virtually all of the warming in the northern hemisphere during the last four decades to increases in average high temperatures at night.

The available literature on the sensitivity of tomatoes to high night temperatures is difficult to interpret because the temperaturedependence of fruit set has not been established, particularly in terms of separating night temperature effects from day temperature effects. Most studies are conducted at only two sets of conditions (high day/high night vs. low day/low night temperatures) or conducted in the field under constantly varying but largely undocumented conditions (e.g., summer vs. spring production in

The cost of publishing this paper was defrayed in part by the payment of page charges. Under postal regulations, this paper therefore must be hereby marked advertisement solely to indicate this fact.

'Former graduate student.
Hanna and Hernandez, 1982). In other cases, only day temperatures were varied (e.g., Levy et al., 1978). Thus, it is fairly clear that night temperatures as well as day temperatures affect tomato fruit set, but the cardinal temperatures have not been determined.

Classical studies of Went and co-workers in the 1940s are often cited as the basis for the importance of night temperature effects in tomatoes. Based on studies in growth chambers (Went, 1945) and in air-conditioned greenhouses (Went, 1944; Went and Cosper, 1945) the critical factor in the setting of tomato fruit was reported to be night temperature, the optimum range being 15 to $20 \mathrm{C}$ (Went, 1944). There are several problems with these early studies, however, because of the inadequacy of the facilities available at the time. These included the necessity of moving plants to varying nighttime regimes after only $8 \mathrm{~h}$, imposition of different nighttime treatments on plants kept in greenhouses during the day at different times of the year, mosaic disease, and the use of growth chambers with poor climate control, and low and spectrally unbalanced lighting. The use of an 8-h day was a particular problem in determining the importance of nighttime temperatures. Kinet et al., 1985, observed that studies where night temperature treatments were longer than day temperature treatments generally concluded that night temperatures were more important than day temperatures and vice versa. Studies by Schaible (1962) and Curme (1962) in air-conditioned greenhouses also showed the importance of night temperatures, but had limitations in terms of seasonally varying irradiance and 8-h days.

Poor fruit set at high night temperature is not well understood in terms of the relative importance of these effects on male and female reproductive tissues. The most definitive work has been done on cowpeas by Hall and co-workers. Warrag and Hall (1984) attributed low podset in cowpeas grown at 33/30C compared to those grown at $33 / 24 \mathrm{C}$, to reduced pollen shed and viability. Podset 
was increased in these plants when flowers grown at lower night temperatures were used as a pollen source. Mutters et al. (1989) associated temperature sensitivity with inhibition of proline accumulation in pollen grains and greater accumulation of proline in anther walls under high night temperatures.

In tomatoes, there is little consensus on whether pollen or ovule effects are more important at high temperatures, and none of this work has targeted night temperature effects. Levy et al. (1978) used cross-pollination experiments on fertile plants to compare male and female effects. They reported that overall, with high daytime temperatures, (nighttime temperatures were the same), effects on male gametes seemed more important than those on female gametes. Reduction in pollen fertility at high temperatures have been noted by Dane et al., 1991 and a decline in pollen germination as germination temperatures increased from 20-27C by Charles and Harris (1972).

It is not clear to what extent reduced pollen production at high temperatures will affect fruit set in tomatoes. Even though a relatively small percentage of pollen produced is required for fertilization, literature on pollen competition (Burd, 1994) suggests that reduced pollen quantity can depress fertilization and viability and vigor of seeds produced. Pollen limitation and pollen competition effects may also be variable with species, and are currently somewhat controversial in the literature (Caspar and Niesenbaum, 1993). In a study of pollen competition effects in apples and pears, Janse and Verhaegh (1993) found pollen density affected fruit set, seedset, and seedling vigor of an apple cross, but the effect was not consistent across the two cultivars and no effect on seedling vigor was seen in the pear cultivar used. In pear, a higher pollen density did increase the number of apparently viable seeds. However, Dane et al. (1991) concluded that more research was needed on the causes of the wide genotypic variation in heat tolerance and the underlying physiological processes. The objective of the present study was 1) to establish a night temperature dependence curve for fruit set in tomatoes and 2) separate male and female effects, at least on a preliminary basis.

\section{Materials and Methods}

Phytotron. Seeds of 'Laura', an indeterminate greenhouse tomato cultivar, (De Ruiter Seeds, Naaldwijk, the Netherlands), were germinated in mist beds starting 1 Sept. 1993. They were then transplanted on 14 Sept. into a $26 / 22 \mathrm{C}$ growth chamber with growing area of $3 \times 2 \mathrm{~m}$. On 30 Sept., 104 four-week-old 'Laura' seedlings were transplanted into 9-liter containers $(25-\mathrm{cm}$ diameter pots) using a 2:1 (v/v) mix of gravel and peat-lite, placed two per cart and assigned to four growth chamber treatments. Day temperatures (0700-1900 HR) in all chambers were 26C. Night temperatures (1900-0700 HR) were: 18C, 22C, 24C and 26C. Night temperature treatments began 1 Oct. 1993, corresponding to visible flowers in the first cluster. Chamber irradiance at the start of the experiment was about $650 \mathrm{mmol} \cdot \mathrm{s}^{-1} \cdot \mathrm{m}^{-2}$ at the base of the plant, provided by a mixture of fluorescent (T-12, 1500-ma, cool-white) and incandescent lights $(100 \mathrm{~W})$. Lamps were replaced on a regular schedule, so the total decrease of chamber lighting attributable to degradation of light sources was no more than $12 \%$ of the initial intensity. Details of growth chamber design and operation, such as formulation of nutrient solution (half-strength Hoagland's) and methods used to avoid $\mathrm{CO}_{2}$ drawdown in the chambers, are provided by Thomas and Downs (1991). Plants were trained to a single stem by removing sideshoots, supported on stakes placed in the pots and watered twice daily. Carts were rotated weekly in the chambers to reduce position effects. Fully opened flowers were pollinated midday by vibration for $3 \mathrm{sec}$ with a commercial electric vibrator.

Pollen sampling and in vitro germination. On four dates (29 Oct., 2 Nov., 3 Nov., and 4 Nov. 1993), pollen samples were collected from open flowers in the first and second inflorescence of 10 plants in each of the four treatments. The pollen samples were collected midmorning (usually $1000 \mathrm{HR}$ ) by vibrating the inflorescence while holding a flower at anthesis in a 50-ml glass vial to collect pollen. Within $30 \mathrm{~min}$ of collection, $10 \mathrm{ml}$ of germination solution (Abdul-Baki and Haynes, 1993) consisting of $20 \%$ lactose by mass, $50 \mathrm{ppm}$ boron and $\mathrm{pH}$ adjusted with potassium hydroxide to 5.2 were added to the vial to begin the in vitro germination process.

Samples were allowed to germinate for $2.5-3 \mathrm{~h}$, then aliquots were examined at $100 \times$ using a light microscope. Pollen grains were classified into the following categories (Fig. 1) germinated (pollen tube longer than diameter of pollen grain); shriveled; underdeveloped or undersized (smaller, darker) grains; and normal in appearance (large, spherical, light-appearing) but ungerminated. Grains were counted by category in five regions on each of four slides per treatment for each of the four sampling dates.

Harvest. At the conclusion of the experiment (4 Nov.), plant height, shoot dry matter, flower and fruit number, and fruit fresh

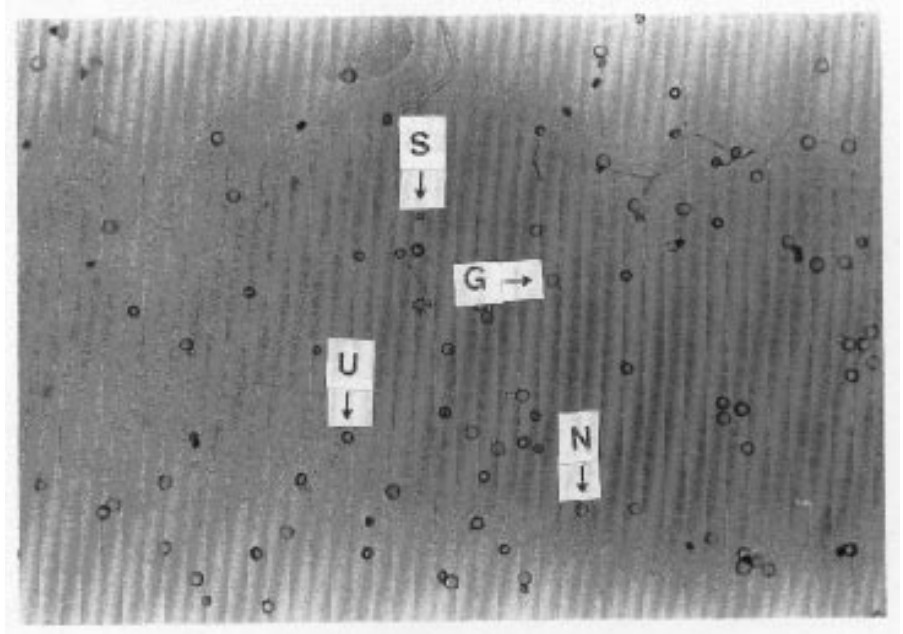

Fig. 1. Field of pollen grains (100×) showing germinated $(G)$, undersized (U), shriveled (S) and normal, but ungerminated $(\mathrm{N})$.

mass were measured. All fruit were still green at this time. All clusters were harvested but only data from the first clusters were used in the statistical analyses and figures presented because not all flowers had reached anthesis in clusters 2 and above in the lower temperature treatments, preventing computation of fruit set. For each fruit, the number of seeds present was rated visually after cutting the fruit in half cross-wise. A fruit with empty spaces in place of gel and few seeds visible received a seediness index rating of 0 , and a fruit with good gel development and many seeds visible received an index rating of 5 .

Pollen application to male-steriles. Pollen was collected as described previously from 10 plants in each treatment and applied with a small brush to cluster 1 (2-3 Nov.) and cluster 2 (10-11 Nov.) of male-sterile plants [NC8288 MS-1035, provided by R. Gardner, North Carolina State Univ. (NCSU)] kept in an NCSU Horticultural Science glasshouse (minimum temperature 24/18C). Two fertile plants of NC8288 (distinguished by purple stems and fully developed anthers) and two extra sterile plants were included in each experimental block as nonpollinated controls.

Plants were arranged on greenhouse benches in four blocks, 
each consisting of 24 plants. Each plant was in a separate 18.9-liter black plastic Grow-Bag (Hydro-Gardens, Colorado Springs, Colo.) filled with Pro-Mix-BX (Premier Brands, New Rochelle, N.Y.) with the plant tied to an overhead wire for support. Side shoots were removed. Flower and fruit numbers were counted in all plants on 19 Nov. 1993. By 24 Jan. 1994, all pollinated fruit were at the breaker stage of development or later. Fruit were harvested, weighed, and rated for seediness. Fruit were bulked by block and temperature treatment and fermented to extract the seeds, which were cleaned, counted, and weighed. Seeds were planted on 16 Feb., 1994. Percentage emergence and fresh mass and dry mass of the seedlings were measured 15 Mar. 1994.

Analysis. Design of the phytotron experiment was completely randomized, with carts rotated several times weekly to reduce position effects within the chambers. The greenhouse experiments were blocked on the benches (randomized complete block design). Data were analyzed with the JMP statistical program (SAS Inst., Cary, N.C.) For any variables in which a one-way analysis of variance (ANOVA) indicated significant temperature treatment effects $(P<0.05)$, pairs of treatment means were also compared using Students $t$ test. Standard errors of the means (using a pooled estimate of error variance) were then calculated for each treatment and linear and quadratic regressions plotted. Overall, $R^{2}$ values were highest and $P$ values most likely to be significant for the quadratic, so these and the standard error already calculated were plotted using Deltagraph Pro 3.5. Percentage data were not arcsin transformed because the range in percentage points was <40 (Little and Hills, 1978).

\section{Results}

Pollen characteristics. Night temperature treatment effects on the following pollen characteristics were significant: number of pollen grains germinated; number of shriveled pollen grains; number of normal-appearing, but ungerminated pollen grains; total number of pollen grains; percentage of pollen grains shriveled; percentage of total pollen grains germinated; percentage undersized and percentage normal in appearance. In most cases where effects were significant as determined by ANOVA, the temperature dependence was best described (highest probability of significance and highest $R^{2}$ values) by a quadratic equation (Figs. 2 and 3). All quadratic equations plotted were significant at the $5 \%$ level. The number of undersized pollen grains was not affected by night temperature treatment.

Overall, these curves suggest both the quantity and the percentage of normal-appearing grains of pollen produced was optimal at a night temperature of about 20C. At higher night temperatures, both the amount of pollen produced, and the percentage normal, dropped off. For number of normal grains and the total number of grains, means at 18 and $22 \mathrm{C}$ were significantly higher than means at 24 and $26 \mathrm{C}$. The percentage of normal grains was significantly lower at $26 \mathrm{C}$ than the other three treatments. The percentage shriveled and percentage abnormal were significantly greater at $26 \mathrm{C}$ than the other three temperature treatments. The percentage undersized was significantly higher at 26 and $24 \mathrm{C}$ than that at the lower two temperatures. The number of shriveled grains was significantly higher in the $24 \mathrm{C}$ treatment than the other treatments, which did not differ. Pollen germination did not follow this pattern, however. Highest germination took place in pollen from the $26 \mathrm{C}$ night temperature treatment. Differences between temperature treatments were all significant for percentage germination but, based on the number of grains, the number germinated at $26 \mathrm{C}$ was not significantly different from that at $18 \mathrm{C}$.

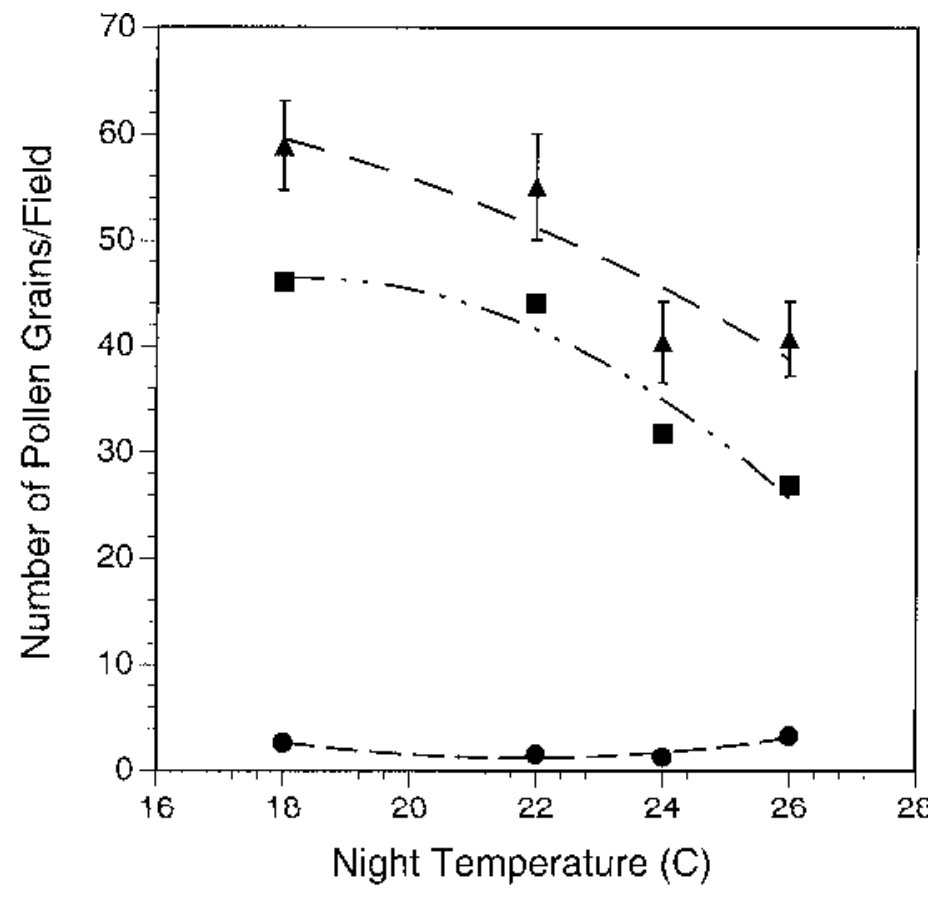

Fig. 2. Effect of night temperature on number of total ( $\mathbf{\Delta})$, normal (ם) and germinated $(\mathbf{O})$ pollen grains $/ 100 \times$ microscope field \pm standard error of the mean (error bars covered by symbol for number of germinated and number of normal). Treatment differences significant using one-way ANOVA at $P<0.05$. Lines plotted for second degree polynomial: number of germinated: $f=52.02-4.675 \mathrm{x}$ $+0.1075 \mathrm{x}^{2} ; R^{2}=0.869$; number of normal: $\mathrm{f}_{\mathrm{x}}=-68.152+12.55 \mathrm{x}-0.344 \mathrm{x}^{2} ; R^{2}=$ 0.927 Number of total: $\mathrm{f}_{\mathrm{x}}=46.145+3.055 \mathrm{x}-0.1284 \mathrm{x}^{2} ; R^{2}=0.838$.

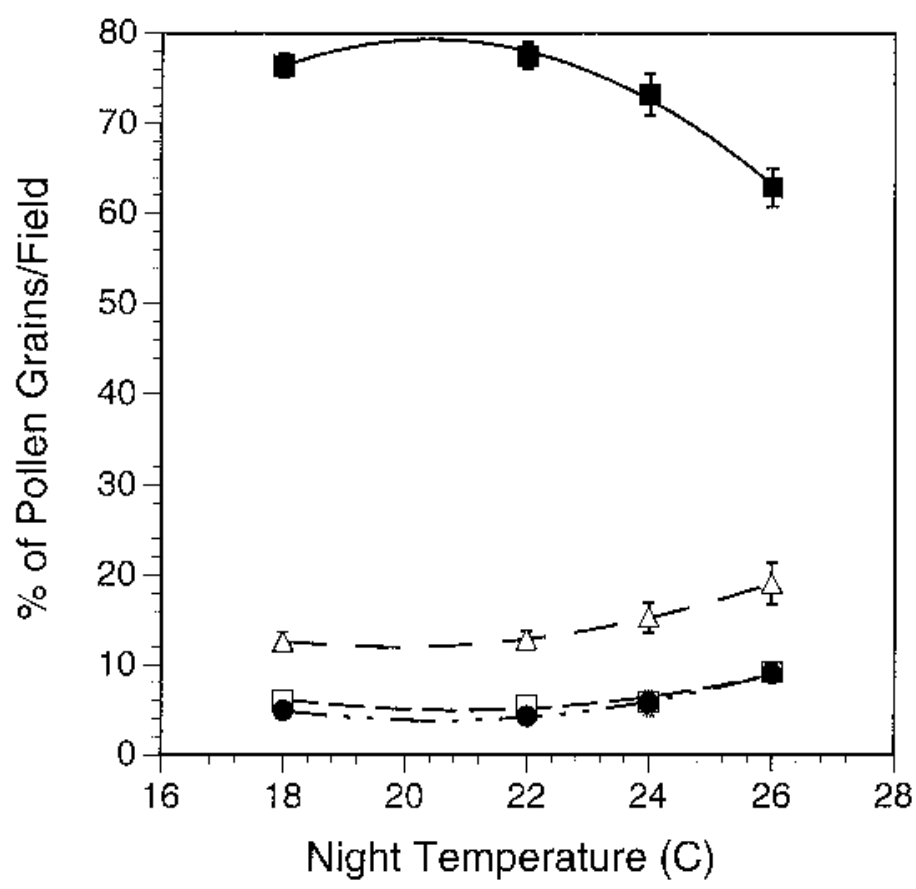

Fig. 3. Effect of night temperature on percentage of normal (ם), germinated ( $\mathbf{0})$, shriveled $(\square)$, and undersized $(\Delta)$ pollen grains per microscope field (on the basis of number) \pm standard error of the mean (error bars covered by symbol for percentage germinated and percentage normal). Treatment differences significant for all variables using one-way ANOVA at $P<0.05$. Percentage normal: $\mathrm{f}_{\mathrm{x}}=-$ $134.97+2.1 \mathrm{x}-5.15 \mathrm{x}^{2} ; R^{2}=0.994$. Percentage germinated: $\mathrm{f}_{\mathrm{x}}=77.76-7.20 \mathrm{x}+$ $0.175 \mathrm{x}^{2} \cdot R^{2}=0.997$. Percentage shriveled: $\mathrm{f}_{\mathrm{x}}=71.22-6.354 \mathrm{x}+0.152 \mathrm{x}^{2} \cdot R^{2}=$ 0.932. Percentage undersized: $\mathrm{f}_{\mathrm{x}}=85.99-7.456 \mathrm{x}+0.1878 \mathrm{x}^{2} ; R^{2}=0.999$. 
Flowering and fruit set. Only data from the first cluster were considered in the statistical analyses because in the younger clusters (up to 4 in the high night temperature treatments), not all flowers in the cluster had reached anthesis. Analysis of variance indicated that night temperature significantly affected both the number of flowers and the number of fruit $(P<0.06$ and 0.001 , respectively). Fruit and flower production were significantly lower in the 26C night treatment compared to the other treatments, which did not differ from each other. Because flower and fruit numbers declined (Fig. 4), the percentage fruit set was not significantly affected by night temperature $(P<0.18)$. Seediness index was significantly $(P<0.0001)$ affected by night temperatures, with fruit produced at the lowest night temperature rated significantly seedier than at the higher temperatures, which did not differ (Fig. 4).

Growth. The effect of temperature on shoot dry mass (excluding fruit) was significant $(P<0.003)$ with shoot dry mass significantly higher in the $18 \mathrm{C}$ night temperature treatment than in the other treatments, which did not differ significantly from each other (Fig. 5). Height was also significantly affected by night temperatures $(P<0.006)$ with plants grown at a night temperature of $22 \mathrm{C}$ significantly taller than plants in the other treatments (Fig. 5). The effect of temperature on fruit mass was highly significant $(P<$ $0.0001)$, with fruit mass on the first cluster significantly lower at the lowest night temperature than in the higher temperature treatments. Fruit production at the next-higher night temperature (22C) was significantly lower than at 26C. Similar trends in fruit mass were seen whether all clusters (data not shown) or only the first cluster was analyzed (Fig. 5). Average mass per fruit was not significantly different at 22 and $24 \mathrm{C}$, but was significantly lower at $18 \mathrm{C}$ and significantly higher at 26C (Fig. 5).

Pollination of male-steriles. The male-sterile test system appeared to function as expected; male sterile plants receiving pollen

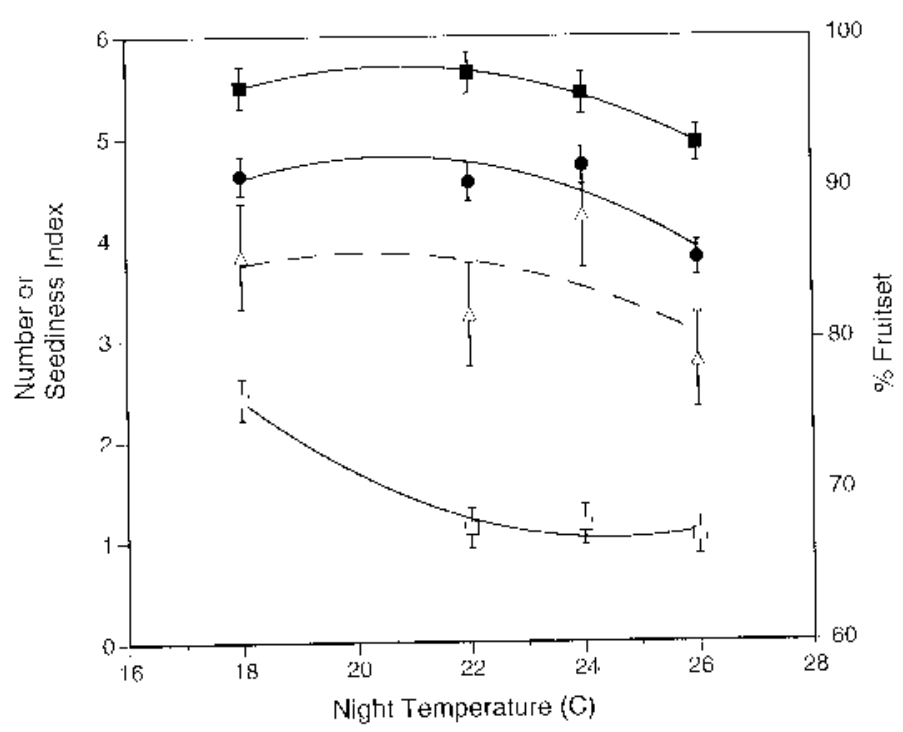

Fig. 4. Effect of night temperature on number of fruit $(\boldsymbol{O})$, number of flowers $(\boldsymbol{\square})$, percentage fruit set $(\Delta)$ and seediness index $(\square)$ in the first fruit cluster at time of final harvest (3-4 Nov.) \pm standard error of the mean. Treatment differences significant for all variables using one-way ANOVA at $P<0.05$. Number of flowers: $\mathrm{f}_{\mathrm{x}}=-6.15+1.143 \mathrm{x}+0.0275 \mathrm{x}^{2} ; R^{2}=0.995$. Number of fruit: $\mathrm{f}_{\mathrm{x}}=-8.83+$ $1.32 \mathrm{x}-0.032 \mathrm{x}^{2} . R^{2}=0.77$. Percentage fruit set: $\mathrm{f}=20.28+6.48 \mathrm{x}-0.1603 \mathrm{x}^{2} . R^{2}$ $=0.278$. Seediness index: $\mathrm{f}_{\mathrm{x}}=20.65-1.60 \mathrm{x}+0.0328 \mathrm{x}^{2} ; R^{2}=0.977$. had significantly higher fruit number and percentage fruit set than unpollinated male sterile plants, and did not differ from selfpollinated fertile controls. We would have expected similar trends in seediness, but seeds were not counted in the unpollinated male steriles or the self-pollinated fertile controls, so effects on parthenocarpy could not be assessed.

The temperature treatment given to the pollen parent had no effect on the fruit number or percentage fruit set of the male-sterile greenhouse plants receiving pollen from the four treatments, as measured about 3 weeks after pollination. There was still no significant effect of temperature on the number of fruit per plant by the time all pollinated fruit were mature, nor was there an effect on the average fruit mass. Temperature treatment to the pollen did not affect number of seeds produced per fruit or seedling characteristics. There was a significant effect on seediness index with fruit from the $22 \mathrm{C} \mathrm{night}$ treatment rated significantly seedier (2.2) than those from the $18 \mathrm{C}$ and $24 \mathrm{C}$ treatments (1.0 and 1.3, respectively) but not the $26 \mathrm{C} \mathrm{(1.5)}$ $(P<0.04)$. There was no significant effect of temperature treatment to the pollen $(P<0.05)$ on total number of seeds, total mass of seeds, mass/seed, number of fruit/treatment, or seeds/fruit. Pollen treatments also did not significantly affect number of seedlings/treatment; total fresh mass of seedlings, total dry mass of seedlings, or percentage emergence of seeds ( $94 \%$ average).

\section{Discussion}

For a number of pollen and growth-related characteristics of tomato plants, night temperatures from 20-24C appeared to be optimal with significantly different means found only in the lowest temperature treatment (18C) or the highest (26C). Seediness was highest at $18 \mathrm{C}$ and fruit number was lowest at 26C. Overall, the effect of night temperature on pollen production, fruit set, and fruit development was less negative than expected from the literature. Fruit set exceeded $75 \%$ in all treatments.

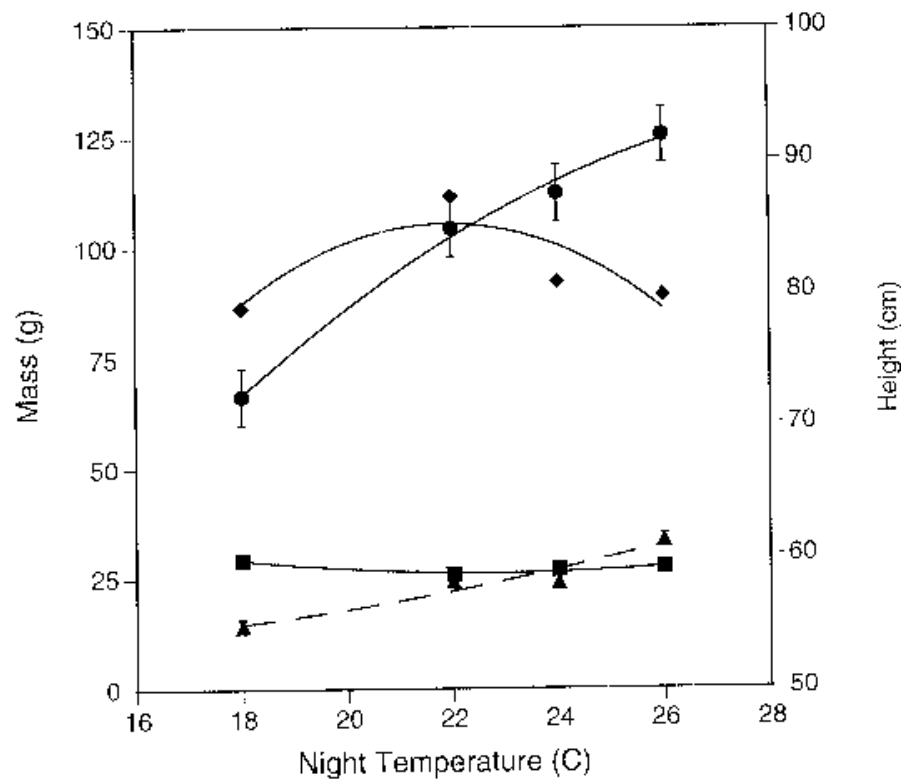

Fig. 5. Height $(\diamond)$, shoot dry mass $(\square)$, total fruit fresh mass $(\bullet)$ per plant and average mass per fruit $(\boldsymbol{\Delta})$ of tomatoes grown at night temperatures of 18,22 , 24 , and $26 \mathrm{C}$ in growth chambers \pm standard error of the mean. Fruit were immature at the time of harvest. Treatment differences significant for all variables using one-way ANOVA at $P<0.05$. Height: $\mathrm{f}=-101.29+17.00 \mathrm{x}-$ $0.3878 \mathrm{x}^{2} ; R^{2}=0.701$. Shoot mass: $\mathrm{f}_{\mathrm{x}}=97.82-6.32 \mathrm{x}+0.139 \mathrm{x}^{2} \cdot R^{2}=0.921$. Fruit mass: $\mathrm{f}_{\mathrm{x}}=260.26+25.8 \mathrm{x}-0.421 \mathrm{x}^{2} . R^{2}=0.994$. Average mass per fruit: $\mathrm{f}_{\mathrm{x}}=23.8$ $-2.405 x+0.105 x^{2}$. 
Acceptable levels of fruit production in plants grown at constant 26/26C temperatures is in contrast to the findings of Went (1944), that no fruit set occurred in a greenhouse kept at a constant $26 \mathrm{C}$ and that fruit production and set as well as weight had a sharp optimum at a night temperature around 19C. The most likely explanation for the differences between the two studies is the low levels of irradiance and short days used in the early studies. Went (1945) observed that in artificial light the optimal night temperature fell off very rapidly with decreasing total illumination. Kinet (1977) studied the effects of different irradiances and daylengths on the incidence of flower abortion in tomatoes. Under 8-h photoperiods with a low irradiance, all flowers in the first inflorescence aborted at $20 \mathrm{C}$ night temperatures. The percentage of flowers that aborted was reduced by doubling the daily irradiance at the same daylength or doubling the daylength at the same irradiance.

Another possible explanation for the relatively high percentage fruit set in the present experiment is that day and night temperatures do not affect tomato fruit set independently. That is, plants are sensitive to mean temperature or accumulated diurnal heat units. There may be a threshold of mean temperature or accumulated daily heat units below which fruit set is not much affected. In the phytotron study, day temperature as well as other conditions such as light were optimal, which may have put even the $26 / 26 \mathrm{C}$ plants beneath a threshold of effects on fruit set even though production of normal pollen was depressed as was seed formation. Although a decrease in pollen fertility has been noted in many studies on tomato (e.g., Dane et al., 1991) the amount and quality of normal pollen may not limit fruit set under optimal conditions and within certain limits (Stanley and Linskens, 1974). When pollen from the plants exposed to high night temperatures was used to pollinate male-sterile plants grown under normal, e.g., nontemperature stress conditions, no effect could be observed on fruit set, fruit characteristics or vigor of the resulting seedlings.

Seediness index and fruit number decreased in plants kept in 26C night temperatures. Curme (1962) also noted a decline in seed content with increases in night temperatures. Abdul-Baki and Stommel (1995) noted that fruit in some cultivars with reported high temperature resistance were nearly seedless, suggesting some high temperature resistance may be related to parthenocarpic fruit development. Declining pollen quantity and an increasing percentage of shriveled and undersized pollen with increasing night temperature could have also contributed to decreased seediness and fruit number. On the other hand, the biological significance of shriveled and abnormal grains is not clear. Their appearance could have reflected an adverse reaction to the in vitro solution rather than defects in pollen production. In any case, inert material and dead pollen are often used as diluents with fresh pollen to lower percent viable grains in a sample. In pine, over a range from $2 \%$ to $100 \%$ viable pollen, seed set was maximal with $10 \%$ to $30 \%$ viable pollen (Stanley and Linskens, 1974).

Higher seed content and fruit number at low temperatures were not associated with greater ability of pollen produced at these temperatures to germinate. The number of germinated grains was similar in the $18 \mathrm{C}$ and $26 \mathrm{C}$ treatments and percentage germination was highest in the $26 \mathrm{C}$ treatment. All germination tests were conducted at the common day temperature of $26 \mathrm{C}$, and high percentage germination in vitro in the $26 \mathrm{C}$ night plants may reflect developmental adaptation to this temperature. Polito et al. (1991) found that optimum germination temperature for walnut pollen increased as a function of increased integrated daily temperature during pollen development. Although low overall, in vitro pollen germination percentages were similar to those reported by Abdul-
Baki and Haynes (1993). It is also not clear to what extent pollen germination as determined by in vitro assays determines seed set. Since a relatively large quantity of pollen is applied to each stigma, the chances of a viable grain setting seed are quite high even with pollen, which germinated poorly during in vitro assays (Stanley and Linskens, 1974). Tomato pollen that did not germinate in vitro still set fruit and often produced as many seeds as fresh pollen (Visser, 1955).

The total and average fruit mass increased over the night temperature range studied, presumably reflecting more rapid fruit development at higher night temperatures. Curme (1962) also reported more rapid fruit development at higher night temperatures.

The highest rate of stem elongation (as indicated by final height in the current study) was not correlated with the highest rate of fruit production, as was also found by Went (1944). Based on greater day/night temperature differentials increasing stem elongation (Myster and Moe, 1995), we expected the tallest plants in the 26/ 18 rather than the 26/22 treatment. However, temperature treatments were imposed for only the second half of the growing period, while DIF effects on plant height are greatest during the rapid growth period (Myster and Moe, 1995). Effects of night temperature on growth also contrasted with Went (1944), who found no consistent effect of night temperatures on shoot fresh mass. We found significantly higher shoot dry mass in plants grown at 18C.

Since effects on fruit number and seediness were relatively small in the phytotron experiment where the entire plant was exposed to high night temperatures, it is not surprising that pollen treatment alone had few effects when applied to nonstressed male steriles. Collecting pollen in a vial and applying it with a brush may have overcome effect of reduced pollen quantity by concentrating it. The introduction of variability by artificial pollination in the male-sterile experiment as well as the normally occurring experimental variability may have also obscured pollen effects.

\section{Literature Cited}

Abdul-Baki, A. and K.G Haynes. 1993. Male fertility of derived tetraploids of Solanum tuberosum from groups Tubersosum x Phureja-Stenotomum. Amer. Potato J. 70:885-894.

Abdul-Baki, A. and J.R. Stommel. 1995. Pollen viability and fruit set of tomato genotypes under optimum and high-temperature regimes. HortScience 30:115-117.

Burd, M. 1994. Bateman's principle and plant reproduction: The role of pollen limitation in fruit and seed set. Bot. Rev. 60:83-139.

Caspar, B.B. and R.A. Niesenbaum. 1993. Pollen vs. resource limitation of seed production: A reconsideration. Current Sci. 65:210-214.

Charles, W.B. and R.E. Harris. 1972. Tomato fruit-set at high and low temperatures. Can. J. Plant Sci. 52:497-506.

Curme, J.H. 1962. Effect of low night temperatures on tomato fruit set. Proc. Plant Science Symp., Campbell Soup Co, Camden, N.J. p. 99-108.

Dane, F., A.G. Hunter, and O.L. Chambliss. 1991. Fruit set, pollen fertility, and combining ability of selected tomato genotypes under hightemperature field conditions. J. Amer. Soc. Hort. Sci. 116:906-910.

Hanna, H.Y. and T.P. Hernandez. 1982. Response of six tomato genotypes under summer and spring weather conditions in Louisiana. HortScience 17:758-759.

Janse, J. and J.J. Verhaegh. 1993. Effects of varying pollen load of fruit set, seed set, and seedling performance in apply and pear. Sexual Plant Reproduction 6:122-126.

Karl, T. R., G. Kukla, V.N. Razuvayev, M.J. Changery, R.G. Quayle, R.R. Heim, Jr., D.R. Easterling, and C.B. Fu. 1991. Global warming: Evidence for asymmetric diurnal temperature change. Geophysical Res. Lett. 18:2252-2256.

Kinet, J.M. 1977. Effects of light conditions on the development of the inflorescence in tomato. Sci. Hort. 6:15-26.

Kinet, J.M., R.M. Sachs, and G. Bernier. 1985. The physiology of flowering. vol. 3. The development of flowers. CRC Press, Boca Raton, Fla. 
Levy, A., H.D. Rabinowitch, and N. Kedar. 1978. Morphological and physiological characteristics affecting flower drop and fruit set of tomatoes at high temperatures. Euphytica 27:211-218.

Little, T. M and F. J. Hills. 1978. Agricultural experimentation: Design and analysis. Wiley, New York.

Moore, E.L. and W.O. Thomas. 1952. Some effects of shading and parachlorophenoxyacetic acid on fruitfulness of tomatoes. Proc. Amer. Soc. Hort. Sci. 60:289-294.

Mutters, R.G., L.G.R. Fereira, and A.E. Hall. 1989. Proline content of the anthers and pollen of heat-tolerant and heat-sensitive cowpea subjected to different temperatures. Crop Sci. 29:1497-1500.

Myster, J. and R. Moe. 1995. Effect of diurnal temperature alterations on plant morphology in some greenhouse crops-A mini review. Sci. Hort. 62:205-215.

Polito, V.S., S.A. Weinbaum, and T.T. Muraoka. 1991. Adaptive responses of walnut pollen germination to temperature during pollen development. J. Amer. Soc. Hort. Sci. 116:552-554.

Schaible, L.W. 1962. Fruit setting responses of tomatoes to high night temperatures. Proc. Plant Science Symp., Campbell Soup Co., Camden,
N.J. p. 89-98

Stanley, R.G. and H.F. Linskens. 1974. Pollen: Biology biochemistry management. Springer-Verlag New York.

Thomas, J.F. and R.J. Downs. 1991. Phytotron procedural manual. N.C. Agr. Res. Serv. Tech. Bul. no. 244 (revised).

Villareal, R. 1980. Tomatoes in the tropics. Westview Press, Boulder, Colo.

Visser, T. 1955. Germination and storage of pollen. Meded Landbouwhogesch 55:1-68.

Warrag, M.O.A. and A.E. Hall. 1984. Reproductive responses of cowpea [Vigna unguiculata (L.) Waalp.] to heat. II. Responses to night air temperature. Field Crops Res. 8:17-33.

Went, F.W. 1944. Plant growth under controlled conditions. II. Thermoperiodicity in growth and fruiting of tomato. Amer. J. Bot. 31:135-150.

Went, F.W. 1945. Plant growth under controlled conditions. V. The relation between age, light, variety, and thermoperiodicity of tomatoes. Amer. J. Bot. 32: 469-479.

Went, F.W. and L. Cosper. 1945. Plant growth under controlled conditions. VI. Comparison between field and air-conditioned greenhouse culture of tomatoes. Amer. J. Bot. 32: 643-654. 